\title{
Las instalaciones industriales de la tierra de Sevilla a finales del siglo XV
}

José Damián González Arce

Universidad de Murcia

\section{Resumen}

Unos informes del concejo de Sevilla de la década de 1490, sobre una serie de pueblos bajo su jurisdicción, nos permiten conocer qué inmuebles se hallaban en ellos dedicados a actividades productivas. Es una documentación excepcional que hace posible diferenciar por comarcas, y en función de otros sectores como la agricultura o el comercio, cuáles de ellas tuvieron mayor dedicación industrial, de qué tipo de sector se trató y por qué se radicó en unos lugares y no en otros; así como su influencia en el crecimiento económico y demográfico local. Para llegar a la conclusión de que la menor dotación de recursos para la agricultura, junto con la disponibilidad de otros como la abundancia de agua para instalaciones molinares u hornos cerámicos, fueron el motor para el crecimiento manufacturero de las regiones más montañosas del reino de Sevilla.

Palabras clave

Molinos hidráulicos; hornos cerámicos; producción de pan; industria rural; relieve montañoso

Códigos JEL: L21, N53, N13, N63

\section{THE INDUSTRIAL BUILDINGS OF THE LAND OF SEVILLE IN THE LATE FIFTEENTH CENTURY}

\begin{abstract}
Some reports of the council of Seville of the 1490s, on a series of towns under their jurisdiction, allow us to know which buildings were in them dedicated to productive activities. It is an exceptional documentation that makes it possible to differentiate by regions and, depending on other sectors such as agriculture or commerce, which of them had greater industrial dedication, what type of sector was the principal and why it was located here and not in others districts; as well as its influence on local economic and demographic growth. To reach the conclusion that the lower endowment of resources for agriculture, together with the availability of others such as the abundance of water for mills or ceramic furnaces, were the engine for the manufacturing growth of the most mountainous regions of the kingdom of Seville.
\end{abstract}

\section{Keywords}

Hydraulic mills; ceramic ovens; bread production; rural industry; mountainous relief

JEL codes: L21, N53, N13, N63

Fecha de recepción del original: 16 de enero 2020; 14 de diciembre de 2020.

José Damián González Arce, Departamento de Economía Aplicada, Área de Historia e Instituciones Económicas Facultad de economía y Empresa, Universidad de Murcia. Campus de Espinardo, 30100 Murcia Tel.: +34 868888752; E-mail: josedam@um.es.

ORCID ID: 0000-0002-3296-0554 


\title{
Las instalaciones industriales de la tierra de Sevilla a finales del siglo XV ${ }^{1}$
}

\author{
José Damián González Arce
}

Universidad de Murcia

1. Introducción

El trabajo que aquí se presenta surge de una pregunta inicial: ¿cómo se explica que algunas de las localidades más pobladas, prósperas y desarrolladas del antiguo reino bajomedieval de Sevilla se encontrasen en la zona más montuosa del mismo? Pues, esta Sierra Norte, o la parte más occidental de Sierra Morena, en el siglo XV las comarcas de la Sierra de Aroche y de Constantina, era el territorio más escarpado y accidentado, sito en el terreno más montañoso, menos fértil y apto para la agricultura. La respuesta solo puede ser una, que esta falta de dotación agrícola se compensase con grandes ventajas comparativas para otras actividades económicas, como la ganadería - como hoy día, con la cría del cerdo ibérico-. Sin embargo, generalmente, este otro sector pecuario no bastaba en el período preindustrial, ni aún combinado con una agricultura de montaña relativamente eficiente, para colocar a las poblaciones de las sierras a la altura en riqueza, ni mucho menos por delante, de aquellas otras de los valles, vegas y llanuras fértiles, dedicadas al cereal - como la Campiña seviIlana, de Utrera ${ }^{2}$ o Lebrija ${ }^{3}$ - , o a otros cultivos especializados de gran calidad, como el olivar — caso del Aljarafe-. Por ello, solamente el haber contado con un sector industrial potente,

\footnotetext{
${ }^{1}$ Este artículo ha sido realizado en el marco del proyecto HAR2017-83801-P“Política instituciones y gobernanza de las villas y ciudades portuarias de la Europa Atlántica en la Baja Edad Media: análisis comparativo transnacional", del Ministerio de Economía, Industria y Competitividad.

2 De la que, aparte de tahonas y hornos, solamente sabemos de una licencia dada en 1492 al carretero Alfonso Martín para un molino de pan en el río Guadalete, entre Villamartín y las Gateras, encima del vado de las Ovejas (el arroyo de Las Gateras desemboca poco más arriba de Villamartín en el Guadalete); otra para Alfonso Martín de Medellín (1504), en el río Salado, en el Rincón del Águila (actual embalse de La Torre del Águila, por tanto); también la hubo para tenerías de cueros en el camino de Los Palacios, dada en 1492 a Pedro García Prieto; y otras 3 para tejares, uno cerca de Los Palacios, en Tamargallo, a Juan de Albornoz (1496), el de Juan de Écija en La Laguna, camino Los Molares (donde hay varios topónimos llamados barreros) y el de Martín García de Astorga, en el arroyo de la Cañada, ambos de 1502; o para ollerías, como las del arrabal nuevo, la de Gonzalo Gómez o la de Francisco de Reina (González Arce, 2020, apéndices y en prensa 1).

3 Ésta, curiosamente, careció de toda instalación industrial más allá de tahonas y hornos de pan para cubrir la demanda de sus vecinos; a no ser un molino de pan, en el Salado de la Reina, camino de Espera; erigido en 1491 por Fernando Benítez y Diego Pedro, albañil (González Arce, 2020, apéndices). Al este de Lebrija, el arroyo Salado, que nace en el Cerro de la Molinera, cruza el antiguo camino de Espera.
}

junto a los anteriores agrícola, de menor importancia que en otras zonas llanas, ganadero y forestal habría permitido a estas comarcas serranas aproximarse, o incluso a veces superar, a las exclusivamente agrícolas. Tal es al menos una de las tesis que explica el posterior desarrollo de la protoindustria, a partir del siglo $\mathrm{XVI}{ }^{4}$.

Es la hipótesis que voy a intentar demostrar en este artículo: una agricultura precaria habría llevado a los habitantes de Sierra Morena occidental a explorar otras actividades productivas, y aprovechar la dotación de recursos de la zona, en especial los hidráulicos (industrias harinera y textil ${ }^{5}$ ), pero también los arcillosos (cerámica y alfarería), para superar incluso a ciertas zonas agrícolas. Veamos los datos de varios pueblos de Sevilla, municipios dependientes jurisdiccionalmente de la capital, a la que pertenecían la mayor parte de sus impuestos y rentas, detraídos de las actividades económicas de cada lugar y agrupados en sus respectivos almojarifazgos locales; entre los gravámenes de los cuales, se encontraban en todos los casos derechos sobre los inmuebles dedicados a labores manufactureras que analizo en este trabajo, bien sobre los de los particulares, a modo de censo o tributo, o bien los de propiedad del concejo hispalense, en concepto de arrendamiento (González Arce, 2020). Pues algunos de tales núcleos más poblados estaban en estas montañas en las décadas de 1480 y 1490, caso de Fregenal, el primero o segundo mayor de todos, según el indicador que se tome, al tiempo que dichos almojarifazgos eran, asimismo, de los más elevados, como se refleja en la Tabla 1:

\footnotetext{
4 Kriedte, Medick y Schlumbohm, 1986; Mendels, 1972; Aracil y García Bonafé, 1974 González Enciso, 1984; Torró Gil, 1994; Carrasco Tezanos, 2006. Sobre la actividad agraria en estas serranías, y su comparación con otras comarcas sevillanas, PérezEmbid Wamba, 1996: 101-104.

${ }^{5}$ No solamente la lanera o pañera, gracias a abundancia de cursos de agua para la instalación de batanes; sino también la linera o lencera, dada la aptitud del territorio para el cultivo de esta materia prima y, de nuevo, la abundancia del agua necesaria para su transformación en fibras textiles (Pérez-Embid Wamba, 1996: 110-111). De hecho, los registros fiscales del siglo XV atestiguan una proliferación del cultivo de lino en la zona, que dio lugar a la segregación de la renta del peso del lino en muchos lugares de esta sierra, de los almotacenazgos y almojarifazgos en los que hasta entonces se hallaba incluida. Sin embargo, esta industria de lienzos no ha dejado muchos más rastros documentales, pues no precisó de instalaciones industriales específicas para su desempeño. Pero sí alguna evidencia: en 1502 el almojarifazgo de Utrera fue recaudado por un fiel, que cobró derechos a varios lenceros, alguno de ellos vecino de Fregenal (González Arce, 2020, apéndices).
} 
Tabla 1: Vecinos de algunos concejos de la tierra de Sevilla, valor de sus almojarifazgos en maravedís, y variación porcentual aproximada de ambos indicadores entre la primera mitad del XV y final de siglo

\begin{tabular}{|c|c|c|c|c|c|c|c|c|c|c|}
\hline Localidad & Año & Vns & Año & Vns & $\%$ & Año & Mrs. & Año & Mrs. & $\%$ \\
\hline \multicolumn{11}{|c|}{ Sierra de Aroche } \\
\hline Fregenal $^{a}$ & 1426 & 504 & 1489 & 1.296 & 157 & \multirow[t]{4}{*}{1426} & \multirow[t]{4}{*}{29.000} & \multirow[t]{4}{*}{1489} & \multirow[t]{4}{*}{128.695} & \multirow[t]{4}{*}{433} \\
\hline El Bodonal & 1435 & 76 & 1486 & 360 & 373 & & & & & \\
\hline La Higuera & 1426 & 51 & 1489 & 348 & 582 & & & & & \\
\hline La Marotera & 1426 & 15 & 1486 & 17 & 13 & & & & & \\
\hline Aracena $^{b}$ & 1426 & 198 & 1485 & 984 & 396 & \multirow[t]{3}{*}{1426} & \multirow[t]{3}{*}{6.482} & \multirow[t]{3}{*}{1485} & \multirow[t]{3}{*}{47.611} & \multirow[t]{3}{*}{734} \\
\hline Hinojales & 1435 & 8 & 1485 & 91 & 1.037 & & & & & \\
\hline Galaroza & 1435 & 8 & 1493 & 56 & 600 & & & & & \\
\hline Aroche $^{c}$ & 1442 & 260 & 1489 & 501 & 92 & 1441 & 4.872 & 1489 & 6.987 & 143 \\
\hline Cortegana $^{d}$ & 1426 & 56 & 1489 & 282 & 403 & 1426 & 2.893 & 1489 & 22.271 & 769 \\
\hline Encinasolae & 1426 & 47 & 1486 & 205 & 336 & & & & & \\
\hline Cumbres S. B. & 1426 & 56 & 1486 & 208 & 276 & 1426 & 1.075 & 1486 & 3.500 & 325 \\
\hline Cumbres M. & 1426 & 204 & 1486 & 302 & 148 & 1426 & 3.000 & 1486 & 20.890 & 696 \\
\hline Zufre & 1435 & 83 & 1489 & 250 & 201 & 1435 & 1.283 & 1489 & 2.000 & 155 \\
\hline Almotgo. S. Aroche ${ }^{f}$ & & & & & & 1441 & 9.240 & 1489 & 8.062 & 87 \\
\hline \multicolumn{11}{|c|}{ Sierra de Constantina } \\
\hline Cazalla & 1431 & 367 & 1486 & 677 & 84 & 1432 & 8.737 & 1486 & 30.052 & 343 \\
\hline Constantina & 1433 & 260 & 1486 & 531 & 104 & 1432 & 7.525 & 1486 & 20.835 & 276 \\
\hline Alanís & 1435 & 276 & 1486 & 483 & 75 & 1435 & 5.482 & 1486 & 13.722 & 250 \\
\hline Castilblanco $^{9}$ & 1406 & 25 & 1489 & 168 & 572 & 1406 & & 1489 & 19.350 & \\
\hline C. Guardas & 1407 & 34 & 1489 & 174 & 411 & & & 1489 & 15.635 & \\
\hline Portazgo C. y A. ${ }^{h}$ & & & & & & 1432 & 17.637 & 1486 & 31.255 & 177 \\
\hline Almotgo. S. Constantina & & & & & & 1432 & 9.675 & 1486 & 10.046 & 103 \\
\hline \multicolumn{11}{|c|}{ Aljarafe y Ribera } \\
\hline Sanlúcar & 1438 & 410 & 1485 & 496 & 20 & 1435 & 7.000 & 1485 & 12.900 & 184 \\
\hline Aznalcázar & 1438 & 200 & 1486 & 291 & 45 & 1435 & 3.407 & 1486 & 9.623 & 282 \\
\hline Hinojos & 1435 & 160 & 1486 & 211 & 31 & 1435 & 4.300 & 1486 & 10.000 & 232 \\
\hline Almotgo.' & & & & & & 1435 & 23.762 & 1486 & 26.875 & 113 \\
\hline \multicolumn{11}{|c|}{ Campiña } \\
\hline Utrera & 1433 & 317 & 1488 & 1.510 & 119 & 1432 & 16.300 & 1488 & 119.649 & 734 \\
\hline Lebrija & 1431 & 407 & 1480 & 760 & 86 & 1432 & 20.000 & 1480 & 60.000 & 300 \\
\hline Alcalá de Guadaira & 1433 & 317 & 1484 & 742 & 134 & 1433 & $109.041^{\mathrm{k}}$ & 1484 & $184.700^{\prime}$ & 169 \\
\hline
\end{tabular}

a. El almojarifazgo de Fregenal (de la Sierra) incluía La Higuera (Higuera la Real), La Marotera y El Bodonal (Bodonal de la Sierra).

b. El almojarifazgo de Aracena incluía a sus aldeas de Hinojales y Galaroza.

c. Sumados almojarifazgo y aduana, partidos que se cobraban por separado.

d. El almojarifazgo de Cortegana incluía al de La Nava.

e. El almojarifazgo de este lugar, por su escaso valor, fue incluido en el de Cumbres de San Bartolomé desde 1401, al menos hasta 1491, cuando reaparece de forma independiente.

f. Los almotacenazgos (renta sobre ciertas compraventas del mercado, el control de ciertas actividades e instalaciones productivas y el de pesos y medidas) se podían arrendar aparte o sus derechos quedar incluidos en los almojarifazgos locales. En este caso, todos los de los pueblos de esta Sierra estaban en un mismo partido apartado; como en la Sierra de Constantina de más abajo.

g. Castilblanco, Castillo de las Guardas y El Pedroso no contaron con almojarifazgo, sino con una exacción sobre el paso de mercancías llamada roda de los caminos, que se recaudó en un partido conjunto hasta 1425 en el que se incluyeron, sin embargo, algunos otros derechos propios del almojarifazgo. Por tanto, los datos de ambas localidades corresponden a esta roda, ahora sí desagregada para cada uno de los pueblos.

h. Además de su almojarifazgo local, arrendado por separado, tanto Cazalla como Alanís contaron con un portazgo (exacción sobre el tráfico de mercancías) conjunto, arrendado aparte.

i. El almotacenazgo de todo el Aljarafe y Ribera se arrendó conjuntamente.

k. Sumados los partidos del almojarifazgo y del molino que allí tenía Sevilla cerca del puente.

I. Sumados los partidos en los que se había desagregado: almojarifazgo, 2/3 del diezmo del aceite, cuartillos del pan, 1/5 del horno Gonzalo Martínez de la Fuente Llana, almotacenazgo, alcabala vieja, renta del jabón y molino del arrabal. Allí había otros molinos sobre el Guadaíra que no eran de propiedad del concejo de Sevilla, como los de la iglesia hispalense, o el Cerrajas, de la Orden de Calatrava (Córdoba de la Llave, 2002: 12; Franco Silva, 1987).

Fuente: Triano Milán, 2018: 300-307; González Arce, 2020, apéndice documental. 
Mapa 1: poblaciones citadas en este trabajo y límites provinciales actuales

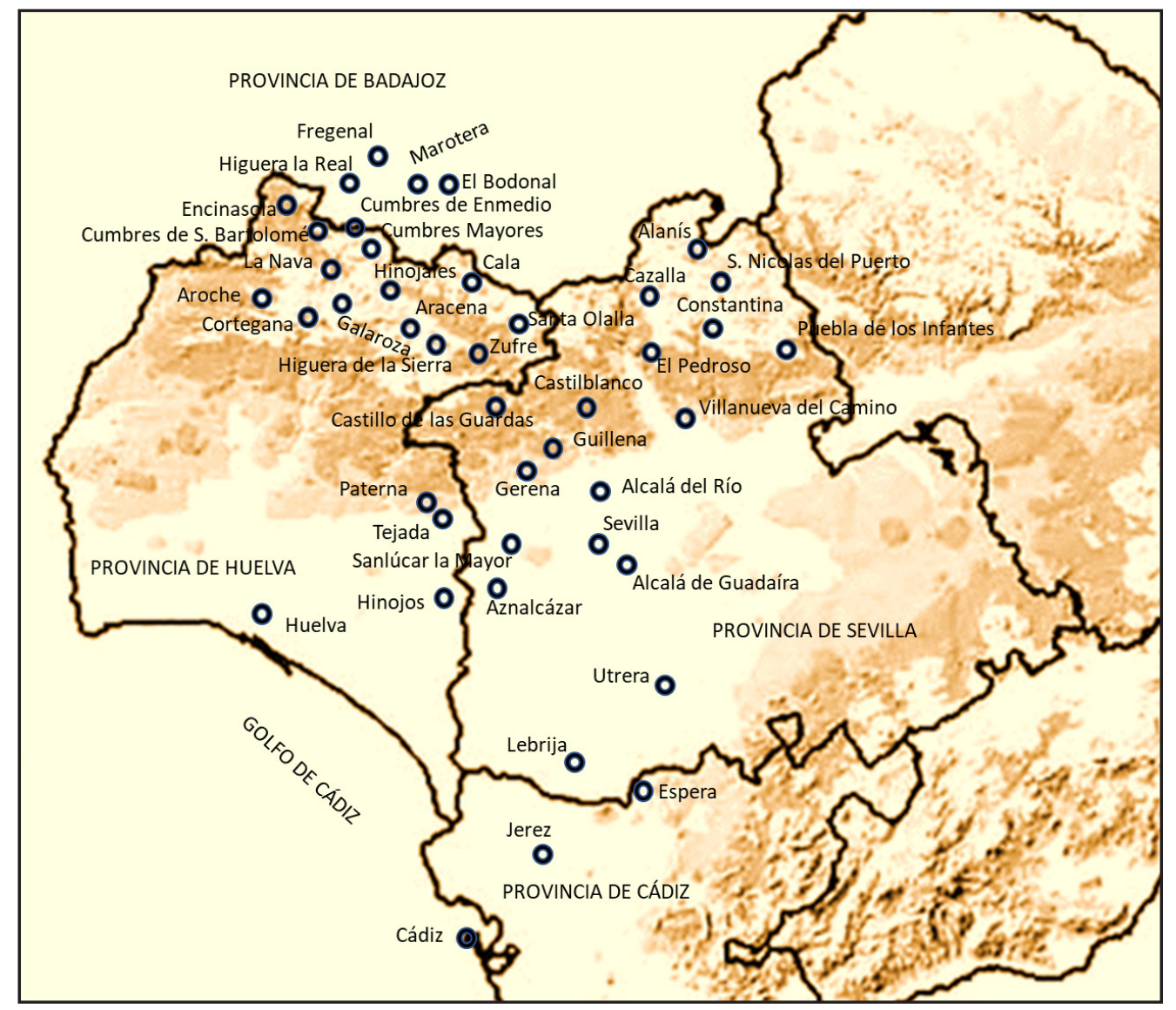

Fuente: elaboración propia.

Los datos anteriores no pueden ser tomados como absolutos - tampoco es necesario insistir mucho en que se trata de indicadores aproximados, y que para la población de la tierra sevillana se han conservado fuentes no muy abundantes, aunque excepcionales para el período, mientras que sí son muy numerosas y extraordinarias en el ámbito fiscal-, pues en el caso de El Aljarafe, tal vez por ser la comarca de mayor riqueza, los concejos eran más pequeños, $y$, por tanto, menos poblados y ricos en términos absolutos, pero no en los relativos, ni en conjunto (Triano Milán, 2018: 300-302). De modo que algunos serranos, caso de Aracena, contaron con numerosas aldeas, como veremos, y eran muy extensos; y otros, como hemos podido comprobar, tenían rentas sobre el tráfico comercial, que engordaron su cuenta fiscal, al estar sitos en las principales vías de comunicación con la Meseta. Cosa que no ocurría tanto en el Aljarafe; pero sí en la Campiña, donde sus alfoces sí eran igualmente amplios, y se encontraban en los caminos principales, en este caso con Granada, Jerez, Cádiz y la costa. Pero puede que el pueblo más próspero de todos, al menos por su contribución fiscal, fuese Alcalá de Guadaíra, en el que, a su actividad cerealera, se unió una importante producción de aceite y aceitunas, con un impuesto o diezmo propio como hemos visto, así como numerosas especialidades industriales, las molinares entre ellas, pero también la producción de jabón ${ }^{6}$. Y es que, en esta tierra llana alcalareña muy apta para la agricultura, se encontraba un curso de agua con numerosos molinos, el río Guadaíra, y estaba muy próxima a la urbe hispalense, a cuya inmensa población abastecía de bienes agrícolas e industriales.

Para realizar este estudio comparativo entre distintos hábitats, comarcas naturales, usos del suelo y actividades económicas, no me voy a detener en cada uno de los casi cien núcleos de población que en estas postrimerías del siglo XV pertene-

\footnotetext{
${ }^{6}$ Que también se registra en las sierras, caso de Cortegana y Aroche (González Arce, 2020). Sobre la población y actividad económica de los pueblos de Sevilla, Bernal Collantes de Terán y García, 1978: 36 y ss.; véanse también los trabajos de Collantes de Terán, 1976, 1977 y 1998.
} 
cieron al señorío de la ciudad de Sevilla, un territorio de unos 12.000 km2 y unos 100.000 habitantes, aparte de la capital; lo que superaría, con mucho, el objetivo aquí propuesto. Sino que voy a aprovechar que en 1491 y 1497 se efectuaron una serie de pesquisas, mediante las cuales el concejo hispalense quería averiguar qué rentas poseía en sus pueblos, entre ellas las comprendidas en el antedicho almojarifazgo, y en las que se nos aporta un listado muy detallado de sus inmuebles dedicados a diferentes especialidades laborales ${ }^{7}$. Las que se han conservado son, en su mayor parte, de las sierras de Aroche y Constantina, pero hay otras de otros lugares, como El Aljarafe y La Campiña, que me van a servir para contrastar sus datos con las primeras. Esta inestimable información será completada con las licencias que los vecinos debieron solicitar al concejo de Sevilla para la erección de estos inmuebles industriales; de las cuales nos han llegado buena parte de las dadas a lo largo del siglo XV. Si bien en el estudio me guiaré principalmente por las antedichas pesquisas, realizadas sobre instalaciones existentes en un momento dado; pues estas otras licencias puede que no se llevasen a efecto o que se correspondan con edificios que luego cambiaron de dueño, o que incluso desaparecieran, lo que podría dar lugar a redundancias (González Arce, 2020).

\section{Instalaciones molinares hidráulicas}

Las características técnicas de los molinos hidráulicos, tanto harineros, de cereales, o de pan, como se decía en la época, como los batanes, o de paños, cambiaron muy poco desde su invención hasta finales del siglo XIX; y, como todavía quedan algunos en uso, es posible el análisis pormenorizado de su funcionamiento. Aquí voy a recoger sus elementos más básicos, que nos permitan saber cómo y cuáles eran los artefactos que se empleaban en las tierras de Sevilla durante el siglo XV (Córdoba de la Llave, 1990: 341-344).

Las aceñas eran la forma más sencilla de molino. Consistían en la instalación de una rueda vertical o azuda en el propio curso fluvial, cuyo eje horizontal al mismo, mediante un sistema de engranajes, movía, gracias a la energía cinética de la corriente de agua, la rueda de piedra de moler, situada sobre una losa fija. El grano era vertido entre ambas y pulverizado por el peso y la fricción de la rueda superior, o muela, sobre la base. A sendas piedras se les practicaban muescas para mejorar la

\footnotetext{
7 Archivo Municipal de Sevilla, Diversos, 602-603, 606-608, 610-616, 719-727. González Arce, en prensa 1. Estas investigaciones fueron encargadas por el concejo de Sevilla. En ocasiones fueron realizadas por sus propios enviados y en otras por los propios consistorios locales, a petición del hispalense del que dependían. Para lo que se comisionó a personas vinculadas a dichos ayuntamientos. Su objetivo fue el conocer el estado de las rentas de los almojarifazgos de estos pueblos que pertenecían a la hacienda municipal sevillana. Qué exacciones comprendían. Sobre qué supuestos se demandaban. Y, cómo se realizaba su recaudación.
}

trituración del cereal. Los llamados molinos de pan emplean el sistema de rueda horizontal o rodezno, con un eje vertical. La muela superior redonda y móvil, gira sobre la inferior redonda y fija, las dos también con muescas, gracias a la energía potencial de un chorro de agua que cae sobre el rodezno o rodete y se transforma en cinética para su movimiento. Este impulso es trasladado a la muela móvil situada sobre el rodezno mediante el antedicho eje vertical o árbol de las piedras. Mientras que el caño de agua proviene de un curso natural que ha sido desviado, con una presa - este término aparece en Cortegana, en un molino del Múrtigas - o azud, para canalizar el líquido en movimiento, gracias al desnivel, a través de una canal artificial o regato hacia la instalación molinar. Para mayor energía potencial, el edificio del molino podía estar semienterrado, y así hacer caer desde más alto el caño de agua que movía el rodezno; tal y como se dice de otro de Fregenal, cuyo hoyo se iba a excavar en lo realengo, junto a la madre y el agua de la rivera de las Huertas. También es posible que este hoyo fuese para almacenar agua cerca del molino y aumentar y garantizar el chorro que caía sobre el rodezno; lo que daba lugar a una variante llamada molino de cubo o represa, frente a los otros de canal o de presa. Ambos tipos se documentan en Aroche hacia $1470^{8}$.

Si bien el primer sistema era el más perfeccionado, pues permitía el mejor aprovechamiento de la energía y una molturación más eficiente, era, con mucho, el menos empleado en las poblaciones que analizo en el presente estudio. El motivo fue que precisaba de cursos de agua considerables y regulares, para mover las grandes ruedas situadas en la madre del río, que escasean en Sierra Morena; donde, por el contrario, abundaban los arroyos y riveras, de escaso caudal y muy irregulares, con severos estiajes estivales y fuertes crecidas ocasionales el resto del año, en función de lluvias estacionales, a veces torrenciales. De hecho, en algunos casos se dice de algunos molinos que no molían por escasez de agua; como el herido (presa y canal o cuérnago) de Juan Hernández, en Las Carboneras (Aracena); o que lo hacían cuando llovía, como depusieron algunos testigos de Aroche en $1497^{\circ}$. La función de estos azudes y canales no era solamente la de recoger agua para mover el rodezno en el momento, para luego retornarla al cauce natural, una vez usada su energía, sino que igualmente alimentaban los depósitos de agua de los molinos de cubo, o los embalses que la almacenaban en previsión de períodos de escasez de caudal del arroyo, e incluso servían para regar huertas y campos anejos a dicho cuérnago o regato del moli-

\footnotetext{
${ }^{8}$ González Arce, en prensa 2; Pérez-Embid Wamba, 1996: 104. Se han conservado las cuentas de 1446 de la reparación de un molino de rodezno sito en Alcalá de Guadaíra perteneciente al concejo de Sevilla, en el almojarifazgo local de esa villa, en las que se detallan los elementos del mismo (González Arce, 2020: 191-192). Aunque parezca sorprendente, no son muchos los estudios publicados sobre molinos medievales castellanos, apenas los hay generales, como los de González Tascón (2009), Rucquoi (1983) y García Tapia (1997). Para algunos estudios de caso, como Córdoba: Córdoba de la Llave, 1990: 342 y ss., y 1993; Toledo: Méndez-Cabeza Fuentes, 1998; Valladolid: García y Carricajo, 1990; Murcia: Martínez Martínez, 1987; y, Antequera: Pérez Gallego, 1992. Para algunas fuentes documentales sobre molinos y heridos de Antequera, Cobos Rodríguez, 2018.

${ }^{9}$ González Arce, en prensa 1. En la relación de Aroche se dice que las tierras sobre las que estaban edificados los molinos no eran riveras caudales, sino arroyos, y no ríos, y molían solamente cuando llovía.
} 
no, como veremos; como se indica para los molinos de Aroche del año 1470 antes citados.

Los batanes eran molinos hidráulicos textiles similares a los harineros, que utilizaban la energía cinética del agua de forma parecida a la vista en los ingenios de parada o de eje vertical, para mover unas mazas que golpeaban y apisonaban los paños de lana, y con ello dotarlos de cuerpo y consistencia (Córdoba de la Llave, 1990: 57-62). En algún caso, como la máquina de la mujer de Luis Hernández Palero, en la Fuente del Rey de Aroche, se dice que podía hacer de molino harinero y de batán, pero no de las dos cosas al mismo tiempo. Lo contrario que el de Pedro Alonso de Las Chinas (de esa aldea aracenense) que, por lo visto, contaba con un molino harinero y un batán diferenciados, pero en el mismo edificio o casa de molino. En algún otro caso se habla también de molinos (harineros) con dos ruedas, como el de los herederos de Gonzalo Sánchez Poso, en Higuera la Real; o los dos asientos del molino de pan de Juan Martínez en Arroyo de los Molinos (Aracena), para los que obtuvo licencia en 1494; los del molino del albañil Juan García, en la rivera del Múrtigas; o el más curioso de todos, el de Gonzalo Vázquez, lugarteniente del escribano del concejo sevillano, que en 1499 ganó una licencia para trasladar su molino de La Nava 15 pasos más adelante, transformarlo en uno de dos ruedas y dos asientos, y construir en su lugar un batán. Mientras que en el arroyo de Los Cubos (Aroche; topónimo que puede haga referencia a los cubos de los molinos de rodezno) encontramos una vega o regato compartido por dos ingenios diferentes (González Arce, en prensa 1 y 2).

Las más detalladas pesquisas de la sierra de Aroche nos aportan, además de lo dicho, algunos otros datos técnicos de sus instalaciones molinares, que no aparecen en las más escuetas de Constantina.

Como he dicho, casi todos ellos, salvo alguna aceña excepcional, eran del tipo molino de pan, esto es de eje vertical, con parada y regato. Este azud se denomina en los documentos de la Sierra de Aroche, no así en la de Constantina, como herido de molino, o el desvío del curso de agua para mover la maquinaria del artefacto hidráulico; también podía ser la cantidad de agua precisa para hacer funcionar el mismo. De manera que muchos de los inmuebles citados en las pesquisas eran, además de los molinos en sí, estos heridos, que en algunos casos carecían de molino; esto es, se trataba de antiguas paradas - también aparece este término otras veces en la documentación- que no contaban con su correspondiente molino, o bien porque todavía no se había edificado o porque se encontraba en ruinas o en desuso. En otros, se habla de molinos recientemente erigidos en antiguos heridos. En ocasiones, se especifica que el molino, a cuyo edificio se refieren las fuentes como cabeza de molino, tenía su correspondiente herido. O que éste formaba una isleta y disponía de una vega, que podían ser privadas o públicas (realengas), o estar en cultivo e, incluso tener árboles, en especial nogales, y huertas. La isleta era el trozo de tierra aislado entre el cauce natural del río o arroyo y la vega que llevaba el agua al ingenio, y que luego, una vez aprovechada para mover sus ruedas y/o regar las tierras adyacentes, la sobrante era devuelta al curso natural. Mientras que la vega era ese regato, cuérnago o canal artificial de agua de ida y vuelta, del arroyo al molino y luego de nuevo al arroyo. Como suele ser habitual y es una estampa típica todavía hoy día, muchos contaban, según las fuentes de la época, con hileras de árboles en sus márgenes, propiedad de los dueños del ingenio, que los aprovechaban económicamente; en especial en Aroche. Además, algunos de ellos, según se dice, por ejemplo, en Galaroza (Aracena), servían de abrevadero para el ganado $y$, si estaban en tierras privadas, conllevaban rebajas fiscales a sus dueños; mientras que, por el contrario, también se pudieron dar licencias a particulares para construir vegas en abrevaderos concejiles (González Arce, en prensa 1). Cuando el molino o su isleta se situaban en el propio cauce del río o arroyo, se dice que estaban en la madre del mismo, que era terreno público (real). Lo normal es que este curso natural de agua fuese público y contase en sus riberas con veredas, o caminos, asimismo públicas o de realengo, como se indica para Fregenal y su rivera de la fuente de las Huertas, donde hubo que realizar por parte de las autoridades del lugar una delimitación de varios molinos que habían invadido el espacio público (González Arce, en prensa 1). El tránsito por estas veredas era libre, e incluso por las isletas de particulares, pero podía estar limitado cuando las tierras y huertas de las mismas estaban sembradas y no se había recogido todavía la cosecha.

\subsection{Sierra de Aroche}

La comarca de la antigua Sierra de Aroche es ahora conocida como Sierra de Aracena y Picos de Aroche, pues, ayer, como hoy, si exceptuamos Fregenal perteneciente a Badajoz, Aracena y su Sierra eran la zona más poblada y económicamente importante de la misma a finales del siglo XV; aunque hasta ese momento lo había sido la antedicha Aroche. Este territorio estaba llamado a ser el más deprimido de toda la tierra de Sevilla, pues a su mayor altitud media y carácter escarpado, se unían como desventajas su lejanía a la capital y su proximidad a la conflictiva frontera portuguesa. De modo que el espectacular desarrollo demográfico y económico que experimentó a finales del siglo XV, tras estar casi despoblado durante la centuria anterior, solamente se explicaría por la puesta en explotación de recursos infrautilizados. De manera que se dice de muchos de los inmuebles que eran de reciente construcción, o que incluso se hallaban en trance de edificación en ese momento de redacción de los informes donde fueron recogidos. De este modo, se ha cifrado hasta en el $45 \%$ los molinos de la pesquisa de 1497 erigidos en los últimos años, en especial en cauces de agua donde no los había con anterioridad o eran más escasos. Lo que no se explicaría por el aumento de la actividad cerealera, que se mantuvo estable - e incluso hubo un mayor incremento de las edificaciones en poblaciones donde el cereal tuvo menor desarrollo que en otras, como Encinasola frente a Cumbres Mayores-, sino para obtener beneficios 
de la molturación de un grano que vendría de fuera, en forma de maquilas anuales; calculadas en algunas ocasiones entre el $5-14 \%$ del valor total del molino ${ }^{10}$. Lo que implicaría, en el mejor de los casos, una amortización de las instalaciones en un período relativamente corto, de algo más de siete años.

Se trata, con mucho, de la comarca de la tierra de Sevilla con mayor concentración de máquinas molinares hidráulicas; sin duda, por su especial conformación orográfica y su clima relativamente húmedo, que nutría uno de los principales afluentes del río Guadalquivir en su cuenca baja, la rivera de Huelva. También es el lugar de nacimiento de otros dos ríos relevantes, el Odiel y el Múrtigas. Y, junto a ellos, de numerosos arroyos y riveras. Esta abundancia de cursos de agua fue determinante para cambiar la fisionomía humana, social y económica de un espacio llamado en un principio a estar poco poblado y no muy desarrollado, debido a su poca dotación de recursos para la agricultura, por ser una zona abrupta y montañosa, como he dicho. Sin embargo, el aprovechamiento de la energía hidráulica para alimentar numerosas instalaciones industriales, junto a otras de otro tipo, hizo de la comarca una de las más pobladas y prósperas de la tierra de Sevilla. Así, en el caso de Aracena, la mayor cantidad de población de su municipio no solamente se debió al crecimiento demográfico de su casco urbano, sino, además, a la aparición a lo largo del siglo XV de numerosas aldeas -lugares con pocos habitantes, pero de hábitat más o menos concentrado y permanente-y montes - parajes menos poblados y de hábitat disperso-. Surgidos para la explotación en muchos casos de estos cursos de agua y sus correspondientes molinos, o de otras actividades industriales como hornos cerámicos (Pérez-Embid Wamba, 1996: 44-45).

Tal proliferación de pequeños núcleos de población en el caso de Aracena, pero también en el resto de localidades de su Sierra, ha hecho preciso dedicarles un estudio específico para determinar dónde se radicaron tan abundantes instalaciones molinares, muchas veces recurriendo para ello a un detenido análisis toponímico, hidrográfico y del relieve (González Arce, en prensa 2).

En Aracena el conjunto más numeroso se localizó en la Fuente del Rey, que en realidad hay que dividir en dos tra$\mathrm{mos}^{11}$. El primero, el arroyo que lleva ese nombre y nace al noreste, cerca del pueblo; un curso de unos $4 \mathrm{~km}$ con unos 35 inmuebles, entre molinos, de ellos al menos 2 batanes, y varios heridos. El segundo, el conocido en el siglo XV como arroyo de los Molinos, que sería el actual barranco de los Molinos, curso final del arroyo de la Fuente del Rey que iba a dar a la rivera de Huelva, y que habría tomado su nombre de una aldea aracenense, allí fundada para la explotación de tales ingenios del final del arroyo de dicha Fuente del Rey. 10 artefactos, que elevan la cifra total de este curso de agua a 45; uno de ellos un batán de paños y frisas y otro batán de paños, frisas y sayales, lo que, junto a los de arriba, nos habla de una pujante industria textil local. El segundo grupo de cauces fluviales aracenenses

\footnotetext{
${ }^{10}$ Triano Milán, 2018: 305; Pérez-Embid Wamba, 1996: 91-92, 103-104. Sobre le erección de molinos como inversión a finales del siglo XV, Sánchez y Mela, 1989: 109-110.

11 Pérez-Embid Wamba, (1996: 87-88, 102-103; y 1998: 134), realizó en su día una aproximación al número de inmuebles productivos de Aracena y su Sierra.
}

con molinos fueron la rivera del Castaño y el arroyo Carboneras, cursos fluviales próximos y paralelos que desembocan asimismo en la rivera de Huelva. Entre ambos contaron con 30 ingenios, incluidos heridos, solo dos en el segundo, al menos uno un batán. El tercer conjunto lo formaron el arroyo de Valdelarco y las riveras de Jabugo, Alájar, Linares y Las Molinillas; la primera tributaria del Huelva, la segunda del Múrtigas, y las restantes del Odiel. Se trata de unos 9 inmuebles molinares, entre heridos y molinos, sin batanes, recogidos de forma desordenada en las pesquisas de 1491 y 1497, en cauces fluviales sin relación entre ellos. Lo mismo ocurre con los 6 radicados en el propio cauce del Odiel y en otras riveras afluentes suyas, como la de Almonaster, Escalada y Seca, que, al menos, sí pertenecían a la misma cuenca. Finalmente, quedan algunos ingenios aislados: uno en el arroyo de la Fuente del Concejo, otro en la aldea del Puerto del Moral y un tercero en el arroyo de la Furraleda (Urraleda, Galaroza). En total, 93 construcciones con uso molinar.

A las que hay que sumar las de otras aldeas aracenenses que contaron con pesquisa propia, como Galaroza, donde se contaron 7 artefactos, uno de ellos batán, en las fuentes de esta aldea o sobre el Múrtigas, ribereño a ella. Mientras que en Hinojales hubo 3 molinos y 1 herido en el arroyo de la Corte, y 1 molino más en la rivera de Hinojales. Lo que lleva a un total de unas 103 instalaciones radicadas en tierras del término de Aracena. Cifra que no puede ser exacta pues a veces se habla de molinos de forma indirecta mediante referencias, o se dice, por ejemplo, que había varios heridos, sin determinar la cantidad.

Si nos vamos a Aroche, vemos que el número de edificios hidráulicos fue sensiblemente menor, pero todavía relevante, en sintonía a su pérdida de importancia relativa frente a Aracena en este final de siglo, como vimos: 12 en la rivera de Chanza, 9 en el arroyo de Los Cubos, 2 en la rivera de Alcalaboza y 4 en el arroyo de la Villa; todos juntos, 27 artefactos. Encinasola estuvo algo mejor dotada: 30 en el río Múrtigas, 7 en el arroyo del Cavá y 3 en la rivera del Sillo; un total de 4012. El almojarifazgo de Cortegana apenas contó con 13 inmuebles en La Nava, sobre el río Múrtigas, aunque dos de ellos fueron batanes ${ }^{13}$. En cuanto a Cumbres, las Mayores registraron 14 en la rivera del Sillo, 5 en el Múrtigas y otros 5 en la rivera de Riofrío; 24 en total ${ }^{14}$. Mientras que su vecina Cumbres de San Bartolomé tuvo 6 en el Sillo y 16 en el Múrtigas; 22 en total. Al norte de estas Cumbres se encuentra Higuera la Real, que entonces estaba comprendida en el almojarifazgo de Fregenal, como sabemos, con sus 28 inmuebles, 26 en la fuente del Gargallo (barranco Molinos de Gargallón), 1 en el arroyo del Álamo y otro en la rivera de la fuente del Cincho; mientras que en la propia Fre-

\footnotetext{
12 En 1492 el veinticuatro Luis Méndez de Portocarrero obtuvo una licencia para erigir varios molinos en la rivera de Múrtiga, en término de esta villa (González Arce, 2020, apéndices).

${ }^{13}$ A los inmuebles de La Nava contenidos en la pesquisa de 1497 hay que añadir tres licencias, dos dadas en 1489, una a Fernando García Bravo, para hacer allí un molino de pan en la rivera de Múrtiga, en la Moraleja; y otra a Alonso de Vargas, asimismo en dicha rivera; y, una última en 1496, a Bernal de Ibáñez; todos ellos vecinos de Cumbres Mayores (González Arce, 2020, apéndices).

14 En 1478 obtuvo licencia para un molino el escribano Juan Fernández (González Arce, 2020, apéndices)
} 
genal hubo 6, en la rivera de la fuente de las Huertas; 32 en total ${ }^{15}$.

De modo que en toda la Sierra de Aracena/Aroche se cuentan, al menos, unas 261 instalaciones molinares jahí es nada!; de ellas, unos 8 batanes. A las que hay que sumar las que no constan en las pesquisas que estamos viendo: caso, por ejemplo, del molino harinero para el que obtuvo licencia en 1449 Gonzalo Martel, sustituto del alguacil mayor sevillano, en un herido junto a la puerta de Zufre, en un curso de agua que venía de las fuentes de su plaza; $u$ otra licencia para otro molino que consiguió allí en 1479 Diego Fernández de Buerna ${ }^{16}$.

\subsection{Sierra de Constantina}

A diferencia de la Sierra de Aroche, ésta contó con mayor extensión espacial y menor número de asentamientos humanos, pero más poblados, pues también estuvo más dotada para la agricultura, en especial el viñedo, más próxima a SeviIla, a la que nutría de vino y otros bienes de consumo, alejada de la frontera $y$, como vimos, sita sobre las principales vías de comunicación con la Meseta ${ }^{17}$. Puede que esta mejor aptitud

\footnotetext{
15 En el almojarifazgo de Fregenal aparecen una serie de molinos propiedad del concejo de Sevilla, que no hay que confundir con los de los particulares que pagaban tributo asimismo a dicho almojarifazgo; entre ellos el molino de Encima y los dos molinos de Pargas. En 1497 la renta de los molinos del trigo de la villa del almojarifazgo local fue pujada por 6.000 mrs. (González Arce, 2020, apéndices y en prensa 2). Probablemente se radicasen en el arroyo de la Parrilla, pues los restantes artefactos localizados en otras riveras eran de vecinos del lugar. Al norte de la localidad se encuentra la fuente de la Parra, que da nacimiento a este curso de agua, junto al Camino de los Molinos. El primero de tales ingenios, según los topónimos actuales, es el de Martín, le siguen, aguas abajo, Molino de Felipe, Molino Número Cuatro, Molino Número Cinco, Molino Número Siete, Molino de Arjona, Cortijo del Batán, Molino del Risco, Molino de Don Franco y Molino de Ceballos. Al este de este último se encuentra el paraje de La Granja, que en el siglo XV era una dehesa frexnense del mismo modo integrada en el almojarifazgo hispalense, junto a tales molinos.

16 Actual fuente del Concejo, que se remonta a esta primera mitad del siglo XV (http://www.conocetusfuentes.com/ficha_detalle.php?id_fuente=85) (González Arce, 2020, apéndices).

17 El principal núcleo de población de la misma fue Cazalla de la Sierra con 677 vecinos, seguida de la propia Constantina, con 483 (Triano Milán, 2018: 305-306). Es una lástima que no se hayan conservado las pesquisas de estas dos importantes poblaciones, que debieron contar con muchos inmuebles industriales. Como el molino de pan cazallero del escribano Juan Sánchez Candil, con licencia de 1488 para hacerlo en la rivera Benalija (que marca el límite municipal con Guadalcanal), en la parte baja del castillo de Mafón de la Breva; los de Pedro de Cervantes (1492), juez ejecutor de la Hermandad, en el Huesna, uno de ellos debajo de los batanes del monasterio de la Cartuja; o el de Juan Sánchez Rodero, entre el arroyo de las Truchas, que abajo veremos, y el batán de Cubero. También hubo un horno cerámico, de Rodrigo Martel (1480). Mientras que Constantina tuvo igualmente algunos molinos, como el de Diego Sánchez Blanco y su mujer, Inés Sánchez, con licencia de 1480; o el del escribano cazallero Juan Sánchez Candil (1488), visto en Cazalla, un batán en la rivera de Huesna, debajo del batán de los Frailes, y encima del prado de las Ranas y del río de las Truchas, entre la isla de Ruy Martín y la isla de Juan Ibáñez (el Huesna es el límite actual entre los municipios de Constantina y Cazalla; al noroeste de la primera, en e confín con los términos de Cazalla y San Nicolás del Puerto, se encuentra el paraje de Los Prados y, un poco más al sur, el arroyo de Las Truchas desemboca en el Huesna). Allí hubo asimismo un tejar del escribano Alonso López (1434), en la Cabeza de la Forca (González Arce, en prensa 1).
}

para actividades agrícolas y comerciales explique el menor desarrollo de su industria, cuando la dotación de recursos naturales para la misma habría sido similar a la vista en la Sierra de Aroche.

De este modo, en esta otra comarca de la tierra de Sevilla, al haber muchas menos instalaciones hidráulicas, en las pesquisas de 1491 y 1497, aparecen casi siempre dispersas entre el resto de los inmuebles industriales, sin epígrafes o apartados propios que las diferencien por los cursos de agua donde se radicaron. Además, los datos que de ellas aportan son también escasos, pues no se suele indicar si estaban contiguas unas a otras, o el paraje concreto donde se edificaron. Por ello no será preciso situarlas sobre un mapa, y me limitaré a señalar sus características fundamentales según los pueblos en los que se localizaron.

Comenzaré de oeste a este, y de norte a sur, para establecer una continuidad con lo visto para la Sierra de Aroche, con la que la de Constantina comparte ciertos valles fluviales, caso, sobre todo, de la rivera de Huelva, que separa ambas comarcas; en su curso alto la arochena y en el bajo la constantinense.

El primer pueblo en el que me voy a detener es en el Castillo de las Guardas, del que menos información tenemos, pues la indagación de 1491 solo comprende el molino llamado del Pladillo, en la rivera de Guadiamar, propiedad de Pedro Rodríguez, como única instalación de cualquier tipo.

Del mismo modo, para Castilblanco (de los Arroyos), la pesquisa de 1491, la única en la que aparece, exclusivamente contiene molinos, sin otras instalaciones productivas. En concreto dos en el Huelva, citados en primer lugar, y cuatro en el Cala; todos ellos harineros, pues no se indica otra cosa. De los que casi únicamente se dice el nombre de sus propietarios, y en algunos casos su profesión y parentela, y su situación tributaria. Aunque algún dato de su ubicación sí se puede deducir. El primero, el de García Fernández de Mesa y de los herederos de Pedro Fernández de Segura, a pesar de estar en esta relación de Castilblanco, parece que se encontraba más cerca de Guillena, esto es, aguas abajo del Huelva, pues tributaba a este otro almojarifazgo. Del segundo castilblanqueño, de los herederos de Antón Fernández, el mozo (tinajero), se aclara que, efectivamente, se hallaba en término de Guillena, sobre la confluencia de ambas riveras, que, por tanto, serían la de Huelva y Cala. Éste estaba, además, encima del molino del tejedor Bartolomé Pérez (que aparece citado, pues, solamente de forma indirecta). En el Cala, que quedaba plenamente dentro del término de Castilblanco, se situaban ya los ingenios de Alfonso Pero, que en ese momento pertenecía al comendador Gonzalo Castillo, vecino de Sevilla; el de Alfonso de Segura, éste también en la confluencia de ambas riveras, pero del lado del Cala y en Castilblanco, por tanto, que puede fuese el arriba visto de Bartolomé Pérez, pues había sido comprado al mismo y a su socio Fernando Pérez por el padre del antedicho Alfonso de Segura; el de Alfonso, hijo de Diego Pérez; y el último, de los frailes de San Francisco, de Sevilla, desbaratado y en desuso. Todos juntos hacen un total de 6 ingenios ${ }^{18}$.

\footnotetext{
18 En 1457 le fue concedida en Castilblanco una licencia para un molino en el Cala a Andrés Fernández, de Burguillos; y en 1460 otra en Guillena a Alfonso Martínez de Sevilla, para otro en el Huelva, donde se juntaba con el Cala, entre Guillena y Castil-
} 
Si nos vamos ahora a El Pedroso, aquí hay un poco de todo, eso sí, entremezclados molinos de todas las clases, con hornos de pan y tejas. Entre los primeros, todos sitos en la rivera de Huesna (o Huéznar), hay que hablar de los molinos harineros de Juan Martínez, jurado y escribano sevillano; dos del bachiIler Alfonso de Cabrera, alcalde mayor de Sevilla que, a falta de aclaraciones en contrario en el documento, serían asimismo de grano; otros dos, junto con un batán de paños, del jurado sevillano Juan de Figueroa, hijo del jurado Juan Martínez, difunto, y de su hermano Pafo de Pineda; y otros dos radicados en el lugar de Malpica —o Malpicas, paraje situado al noreste del pueblo, junto a un meandro del Huesna, en su margen izquierda-, ambos derruidos, uno de Juan González, escribano de Sevilla, y otro de los herederos de Pedro Sánchez Santocristo y de los herederos de Juan Fernández del Abad. En cuanto al otro batán de la relación, igualmente en ruinas, había pertenecido a Pedro Rodríguez el viejo, lindaba con el molino del susodicho bachiller Alfonso de Cabrera, y había sido vendido hacía poco a Diego Rangel, canónigo de Sevilla, por entonces difunto, por lo que era propiedad su sobrino. En total, 9 instalaciones, 2 de ellas batanes.

Algo parecido ocurre con La Puebla de los Infantes, con inmuebles menos numerosos, no agrupados por epígrafes. De ellos, 3 molinos, como siempre harineros, si no se dice nada en contrario, de los que no conocemos los propietarios: el llamado de Retortillo — río que discurre al este del pueblo—, el del Infierno, en el arroyo de la villa —el arroyo del Infierno nace cerca de la población y va a morir al antedicho Retortillo, paralelo al mismo se encuentra el Camino de los Molinos-y el conocido como Ingorrilla ${ }^{19}$.

Si dejamos las sierras del norte del reino de Sevilla y bajamos al valle del Guadalquivir, donde desembocan las riveras de Huelva y Huesna, arriba vistas, nos encontramos con Villanueva del Camino (hoy del Río). Aquí, en cuanto a instalaciones molinares se refiere, que aparecen entremezcladas con otros inmuebles en la averiguación de 1491, se distingue entre molinos de pan (harineros), entre los que hemos de contar aquellos edificios de los que no se indica su especificidad, como siempre; aceñas, esto es, molinos harineros sitos sobre el propio cauce de agua natural y de eje horizontal, frente a los restantes que, como sabemos, estaban en regatos y con eje vertical; y, batanes. Entre los primeros, el de Álvaro Camacho en la rivera de Galapagar - hoy arroyo, que muere en el Guadalquivir, poco más abajo del pueblo-; curso de agua donde estaba también el de Juan García Zamorano. Otros ingenios se encontraban en el Huesna, que desemboca curso abajo, caso del molino de los frailes de San Jerónimo; y de dos paradas de molinos (molinos de presa o azud) más un batán y molino pertenecientes a Leonor García, la Marchaca, uno de

blanco. Villa en la que en 1447 obtuvieron permiso para otro molino en el Huelva Bartolomé Pérez, Antón Martínez Vela y Bartolomé Hidalgo, vecinos de Castilblanco; algunos de estos ingenios son los que hemos visto en las pesquisas antedichas. Mientras que en 1504 Alfonso Hernández de Breas y Alfonso García Cardenal fueron autorizados en Castilblanco a erigir un molino de pan en el arroyo del Padre e Hijo, afluente de la rivera de Cala, que nace al norte del pueblo, cercano a él, y discurre hacia el suroeste hasta dicho Cala (González Arce, 2020, apéndices).

${ }^{19}$ En 1485 le fue dada licencia para un molino en la rivera del arroyo Agudo a Diego Alonso (González Arce, 2020, apéndices). ellos, llamado de Nicolás Pérez, de su propiedad, por el que pagaba almojarifazgo, y otros dos arrendados a los frailes de San Jerónimo y a una dueña sevillana. Junto a todo esto, el primer propietario citado, Álvaro Camacho, poseía unas aceñas en las propias riberas del Guadalquivir. De un último molino solo se nos dice que era llamado del Palomar, pero no en qué sitio estaba; aunque cercano al Huesna — al noreste de la actual Villanueva el Río y Minas hay un paraje conocido como Los Palomos-. 8 ingenios en total, uno de ellos batán.

Por lo que se refiere a Alcalá del Río, con encontrarse igualmente sobre el Guadalquivir, no aparece en la pesquisa molino alguno, salvo un horno y dos tahonas, que luego veremos. Precisamente la presencia de tales tahonas suele darse en lugares sin cursos de agua aprovechables para instalaciones molinares hidráulicas, que en esta villa sería el caso del Guadalquivir, tal vez demasiado caudaloso e imprevisible en cuanto a sus crecidas en esta zona del río.

De este modo, esta Sierra de Constantina, que he adelantado tuvo menos instalaciones industriales, solamente reunió unos 27 ingenios molinares, de ellos únicamente 3 batanes, según las pesquisas de 1491, frente a los más de 250 vistos para la de Aroche.

Además de en los molinos contenidos en las pesquisas de 1491 y 1497, en esta Sierra hubo otros muchos, sobre todo en los pueblos para los que no se han conservado estas relaciones. Entre ellos los catorce harineros del Huesna en San Nicolás del Puerto. Se trató de unos ingenios que constituyeron un partido diferenciado dentro del almojarifazgo de los pueblos de Sevilla, y que tributaban al almojarifazgo la cuarta parte de lo que rentasen ${ }^{20}$.

\subsection{Aljarafe}

Sanlúcar la Mayor tuvo sus molinos de pan moler en la rivera de Guadiamar, que discurre cercana a la misma, de norte a sur, según el último epígrafe de su pesquisa de 1491. Apenas dos: uno llamado de Juan Maestro, propiedad de Antón Bernal, jurado sevillano; y otro el Molino Nuevo, del comendador

\footnotetext{
20 Este partido de los molinos del Huesna aparece en el almojarifazgo por sí mismo desde 1413. Entre ellos, había uno de la Iglesia, que en 1491 Antón Rico tenía en censo. Hacia mediados de siglo este partido no comprendía el censo del batán del veinticuatro Suero Vázquez de Moscoso, sito en dicha rivera. En 1496 el veinticuatro sevillano Lope de Ágreda obtuvo una licencia para un molino de pan en esta rivera de Huesna, entre el batán de Martín González y la presa del batán del monasterio de la Cartuja, por lo que debía pagar a la renta del cuarto de los molinos del Huesna el 25\% de su maquila. En 1483 Pedro de Ribera poseía unas herrerías en San Nicolás del Puerto -en las que contaba con un privilegio para hacer carbón de la madera del retalle y de lo seco del robledo existente en Constantina-, que quería demoler y edificar en otra parte; mientras que en su solar pretendía construir un molino de pan o un batán. De modo que se encargó una investigación para averiguar si estas herrerías perjudicaban a los molinos sitos en la rivera de Huesna (González Arce, 2020, apéndices y en prensa 1).
} 
Cabrera, veinticuatro hispalense. Por ello, una villa tan poblada precisó de numerosas tahonas que luego veremos ${ }^{21}$.

Aguas abajo del Guadiamar, en Aznalcázar, ribereña al río, encontramos las últimas instalaciones hidráulicas, en su inquisición desordenada de 1491: cinco paradas de molinos de pan, uno de los herederos de Diego de Fuentes; otro de Francisco de Pineda y de la mujer y herederos de Diego de Almonte; el de los herederos del Mariscal; los del jurado Rodrigo de SantiIlán; y, el de Gonzalo Martel ${ }^{22}$.

\section{Tahonas}

Estos molinos de cereal tenían un funcionamiento muy similar a las antes vistas aceñas, pero la energía que empleaban para mover las muelas de piedra no era la cinética de los cursos de agua, sino la muscular de animales de tiro, asnos, mulas e incluso caballos ${ }^{23}$; los cuales daban vueltas alrededor de la piedra fija para hacer rotar sobre ella la móvil, a la que estaban conectados mediante un mayal. Al ser menos eficientes y caras estas formas de obtención de energía, hemos de entender que eran empleadas dichas tahonas en lugares donde, por motivos climáticos o por el relieve, no se podían instalar los molinos hidráulicos, al escasear los cursos de agua, o no ser del caudal preciso; algo ya apuntado anteriormente (Córdoba de la Llave, 1990: 345).

Como se puede comprobar más abajo, existieron tahonas de 1 a 3 piedras, esto es, instalaciones con hasta tres de estas muelas impulsadas por equinos. Pero también las hubo maneras (manuales), movidas por la fuerza muscular humana. En muchos casos, solamente tributaban al almojarifazgo cuando molturaban cereal, de manera que cuando no lo hacían, y para evitar fraudes, sus propietarios debían entregar los hierros que conectaban las bestias al eje de las muelas al almojarife o almotacén local, lo que impedía su funcionamiento (González Arce, 2020: 60)

Efectivamente, en la Sierra de Aroche, dada la abundancia de molinos hidráulicos apenas se registran tahonas en las pesquisas de 1491 y 1497: dos en Aroche —una de dos piedras, de Alonso González, panadero; y otra de una piedra, de Martín Benito, junto a la anterior, en sus casas - que, al estar más poblada y contar con menos molinos de agua que otras poblaciones vecinas, según vimos, habría precisado de ellas para alimentar a sus vecinos o para molturar cereal en los pe-

\footnotetext{
21 No obstante, en 1491 le fue dada una licencia a Fernando Sánchez, vecino de Aznalcóllar, para hacer un molino de pan en la rivera de Cañaveroso, camino de Aznalcóllar, en la parte baja del palacio de los Tres Pinos (González Arce, 2020, apéndices).

22 Ya en 1374 consta la existencia de una aceña en esta localidad perteneciente al concejo hispalense (González Arce, 2020: 59).

23 De la tahona de Alfonso Fernández del Jurado, se dice en 1491 que no molía porque no tenía cebada para dar de comer al caballo.
}

ríodos de estiaje fluvial; otra en Cumbres Mayores — de Alonso Martínez Camacho, en sus casas-; y, otras dos en Fregenal-La Higuera — de nuevo en casa de sus propietarios, Fernando Álvarez, y Pedro Pascual- . Frente a ellas, la localidad de Hinojos, en el aljarafe onubense, que prácticamente carecía de molinos hidráulicos ${ }^{24}$, manifestó en la inquisición de 1491 tener nada menos que 11 tahonas, todas de una piedra, pues no se dice nada en contrario, para sus 211 vecinos (censo de 1486; Triano Milán, 2018: 301). Lo que hace una ratio de 0,025 piedras o muelas por vecino.

Algo similar se puede decir de la Sierra de Constantina, donde no aparece ninguna tahona, pues allí estaban, como vimos, los molinos harineros del Huesna, por lo que no se habrían concedido licencias para este otro tipo de instalaciones molinares no hidráulicas, que habrían podido perjudicar las rentas concejiles hispalenses con su competencia con dichos molinos. Por contra, como con Hinojos, otras localidades de la actual provincia de Sevilla presentes en las antedichas pesquisas y menos dotadas de recursos hídricos, registraron muchas tahonas. Veámoslas de mayor a menor: Lebrija, en plena comarca cerealera de La Campiña y con 760 vecinos en 1480, tuvo, según la averiguación de 1491, 9 de una piedra, 10 de dos y 2 de tres; lo que da una ratio de 0,04 muelas/vecino, casi el doble que en Hinojos, aunque aquí ni hubo molinos hidráulicos y de algunas de estas lebrijanas se dice que no estaban en uso. Ciertas de tales tahonas estuvieron asociadas a hornos de sus mismos propietarios, lo que hizo de ellas auténticas fábricas panificadoras. Este hecho y la mayor presencia de estos molinos de varios asientos o piedras, nos habla de un mayor carácter industrial de la fabricación de harina y pan cocido en una villa que, por su mayor cantidad de población, hacía factible la edificación de instalaciones más eficientes, que aprovecharan las economías de escala al reunir varias muelas y/o un horno. En Sanlúcar la Mayor (con 496 vecinos en 1485), su cuestionario de 1491 recoge sus tahonas en un epígrafe situado en primer término, con un total de 27 de un asiento, pues así se indica expresamente; una ratio de 0,05, muy similar a la de Lebrija. Si bien aquí no se dieron las antedichas economías de escala de las varias muelas por edificio y la asociación a hornos. Puesto que, una menor población hacía que fuese más arriesgado a un mismo propietario invertir en varias piedras, dado que, en caso de bajada coyuntural de la demanda, más probable cuantos menos habitantes había en un lugar, se hacía más posible la quiebra, pues también era mayor y a más largo plazo la amortización de dicha inversión, que solo en ese más largo plazo se traducía en mayores beneficios gracias a dichas economías de escala. Por lo que respecta a Aznalcázar (con 291 vecinos en 1486), en 1491 tenía apenas 8 tahonas de 1 asiento, una ratio de 0,027, pero de nuevo, como en Hinojos

\footnotetext{
24 Excepto el asiento de molino radicado en el arroyo de la Mayor, que discurre de noroeste a sureste al sur de la localidad, propiedad de Gonzalo de Cuadro. Hacia finales del siglo XV y principios del XVI se documentan en la zona realenga (de la tierra de Sevilla) del Aljarafe y Ribera unas 110 tahonas, más algunos molinos de mano para e autoconsumo. Al margen de las pesquisas, en 1480 fue concedida una licencia para un molino de pan a Pedro de las Roelas (González Arce, 2020, apéndices). Y, Entre 1472 y 1474 se dieron cuatro más para otros tantos molinos en Tejada a Rodrigo de Ribera, regidor de Sevilla, entre el Huelva y el Guadalquivir y en los Caños de Tarifa (Borrero Fernández, 1983: 320-321, y cuadro 16 del Apéndice)
} 
(curiosamente casi con la misma proporción), porque vimos contó con 5 paradas de molinos de pan en el río Guadiamar. Finalmente, Alcalá del Río únicamente tuvo 2 tahonas, y Villanueva del Camino ninguna, pues dispuso de numerosos molinos de agua, como sabemos.

\section{Hornos de pan}

Se sabe poco de sus características técnicas, pero tampoco serían muy complejas ni se diferenciarían gran cosa de los muchos hornos de leña que hoy siguen en funcionamiento (Córdoba de la Llave, 1990: 353 y ss.). Sí hay que señalar que los contenidos en las relaciones de 1491 y 1497 eran instalaciones de particulares o del concejo destinadas a cocer el pan de los vecinos, a cambio del pago de una tasa en pan cocido, o poya, o a cocer pan para su venta, esto es, no los hornos privados para la cocción destinada al autoconsumo, que no estaban gravados con exacciones incluidas en los almojarifazgos locales.

Aquí, mejor que con las tahonas, resulta pertinente hacer una relación entre hornos y habitantes de cada lugar, pues no hubo, como en el caso de los molinos, variantes en el tipo de hornos que las distorsionen. Si bien los de particulares para el autoconsumo y los que no estaban en uso sí que nos han de llevar a ser precavidos en este tipo de indicadores del grado de poblamiento o actividad industrial de las localidades del período feudal.

Al parecer, los pueblos de la sierra de Aroche debieron de contar con alguna exención fiscal en este tipo de instalaciones, pues no aparece ninguna en las relaciones de 1491 y 1497, ni siquiera de Fregenal, la villa más poblada de toda la tierra de Sevilla (1.296 vecinos), por encima de Utrera (1.510), si incluimos La Higuera (348) y El Bodonal (360). De modo que de toda la actual provincia de Huelva solamente disponemos de datos para Hinojos, en el Aljarafe, como sabemos. Sus 211 vecinos fueron alimentados mediante tres hornos de pan de poya, una ratio del 0,014 .

En la Sierra de Constantina también parece que existió algún tipo de exención para la cocción del pan, pues solamente aparecen hornos en La Puebla de los Infantes y El Pedroso, para los que no contamos tampoco con datos demográficos; 4 en total en la primera villa y 5 en la otra. Vayamos, por tanto, al resto de localidades de la actual provincia de Sevilla: Lebrija y sus 760 vecinos dispusieron de 21 hornos, una ratio del doble de la Hinojos, del 0,027; como corresponde a un núcleo más poblado y urbano, con mayor oferta de instalaciones productivas, cuyos vecinos, acudían en mayor medida a cocer su pan a hornos ajenos especializados en la cocción al público, que en los suyos propios, al tiempo que consumían más pan cocido comprado en las antedichas panificadoras que en otras partes. Sanlúcar contó con 6 hornos para 496 vecinos; una ratio de,
0,012, casi como Hinojos. Y, otros 6 más en Aznalcázar, para sus 291; una ratio de 0,020, casi como la de Lebrija. En Villanueva del Camino hubo un horno y en Alcalá del Río otro.

\section{Hornos cerámicos}

El barro especial, o arcilla, para elaborar objetos cerámicos, ladrillos y tejas era obtenido de los barreros, desde donde era llevado a los alfares. Allí se mezclaban varios tipos de esta materia prima, a la que se le daba la consistencia deseada añadiéndole agua en unas pilas, o coladeros, en las que era removida con palos. Tras ello se tamizaba, secaba y pisaba, con lo que quedaba lista para ser trabajada. Una vez recibida la forma deseada, mediante moldes o en el torno, la obra era cocida en el horno, u hornos - normalmente hasta dos por alfar- ${ }^{25}$.

Para Aracena, la pesquisa de 1497, como vimos para los molinos, agrupaba los hornos de cocer barro por epígrafes; distingue, como voy a hacer aquí, entre los de tinajas, de ollas (cacharros de barro de menor tamaño) y tejas y ladrillos. Mientras que, en la relación de 1491, como para los ingenios hidráulicos, estos hornos, que en algunos casos son los mismos que los de la otra averiguación, están recogidos sin orden alguno, entremezclados con los molinos. No obstante, no siempre esta división por especialidades cerámicas aparece del todo clara. Así, por ejemplo, del primer horno de 1491, el del ollero Fernando García, se dice que era de cocer teja, ladrillo y ollería; mientras que en la investigación de 1491 este horno del ollero Hernando García aparece en el epígrafe de los hornos de ollas, sin que se aluda a que pudiera haber cocido tejas o ladrillos. Lo mismo se puede decir de Hinojales, cuyos hornos industriales se encuentran en la susodicha pesquisa de 1497 diferenciados en epígrafes entre los de tinajas, los tejares y los hornos de cal. Igual ocurrió en Aroche, donde en 1485 el concejo hispalense accedió a que el ollero Juan Jimeno edificase en sus casas un horno de tinajas, ollas, cántaros, tejas y ladrillos (González Arce, 2020: 68).

El análisis de estos inmuebles productivos lo voy a realizar, por tanto, intentando diferenciarlos por su función principal, siempre que sea posible. Para lo que voy a comenzar con los de mayor carácter urbano, sitos en las propias villas o sus arrabales, para intentar localizar luego los de sus aldeas (lugares más poblados fuera del casco urbano del pueblo) y montes (parajes sin apenas concentración demográfica).

\footnotetext{
25 Córdoba de la Llave, 1990: 324-330. En el almojarifazgo de Fregenal había una renta llamada del barro, sin duda sobre alguno de estos barreros de la localidad; aparte de ésta de la propia villa, también hubo otra del barro de La Higuera.
} 


\subsection{Hornos de tinajas}

Se trata, como se puede suponer, de alfares especializados en grandes objetos cerámicos destinados al almacenaje de productos, con distintas capacidades; desde las más grandes, 50 arrobas, tinajas gigantes hechas con fines industriales (para contener aceite, vino, grano, harina, sal...), a las más pequeñas, de media arroba, para uso doméstico (Córdoba de la Llave, 1990: 324-330).

Comienza la relación aracenense de 1497 con el horno de Esteban Domínguez, que lo había comprado a Juan Vicente. Estaba hecho cerca de San Sebastián, en un solar de su propiedad. En las afueras de Aracena, hacia el sureste, en el camino de Sevilla, se encontró desde mediados del siglo XV la cofradía y hospital de San Sebastián - que era propietaria de un molino en la rivera del Castaño-, en medio de una zona de huertos. Hoy día allí se halla el cementerio del pueblo, del mismo nombre (San Sebastián). El agua necesaria para estas instalaciones industriales se tomaría de una fuente cercana, ahora llamada de Santo Domingo, que actualmente se encuentra al fondo de la plaza homónima y al lado de la iglesia de tal nombre ${ }^{26}$. Se da la circunstancia de que el antedicho hospital de San Sebastián, de ladrillo y en estilo mudéjar, fue habilitado a finales del siglo XVI como convento de Santo Domingo (Pérez-Embid Wamba, 1996: 78)

El segundo de estos hornos de tinajas perteneció a los vecinos de la aldea de Los Caños, que solamente pagaban el 10\% de lo fabricado en el mismo al almojarifazgo sevillano. A falta de una aldea o campo con este topónimo, hemos de pensar que se trata de la actual fuente de los Doce Caños que da lugar al nacimiento del río Múrtigas, en Fuenteheridos; que sería la surgencia que alimentaría estas instalaciones de producción de objetos de barro. Así, hasta entrado el siglo XVI, hacia 1512, no aparece el topónimo de Fuenteheridos en los padrones fiscales, por lo que este núcleo de población se habría denominado hasta entonces como Los Caños (Pérez-Embid Wamba, 1996; 50). Del tercero, el de Leonor Gómez, mujer del difunto Antón Fernández, no se indica su ubicación.

En Hinojales, como sabemos aldea aracenense, se encontró otro horno de tinajas, radicado junto a las casas del pueblo, en el ejido del lugar — puede que se trate del actual paraje de La Dehesa, a $1 \mathrm{~km}$ al sur de la localidad, en la rivera de Hinojales, de donde se surtiría de agua-; en un solar que le dio el concejo a Ruy García, tinajero, quien lo edificó. También cocía tejas, de las que pagaba diezmo; pues las tinajas estaban exentas, según el arancel de almojarifazgo dado en 1493 por los Reyes Católicos ${ }^{27}$.

En el resto de la Sierra de Aroche solamente encontramos tinajerías como tales en Cumbres Mayores: un horno de tinajas, junto a otro de ollas, perteneciente al hospital de San Miguel —que a buen seguro, tendría su sede en la iglesia de localidad,

\footnotetext{
26 http://www.conocetusfuentes.com/ficha_detalle.php?id_fuente=6856.

27 En 1494 Juan García, el mozo, hijo de Diego Fernández, obtuvo una licencia para una tinajería en Aracena, en un solar suyo (González Arce, 2020, apéndices).
}

bajo advocación de San Miguel Arcángel, cercana al castilloal que sus arrendatarios pagaban poya de cada cocción; como pertenecía a esta institución caritativa, estaba exento de almojarifazgo, que tampoco se acostumbraba a pagar por las otras instalaciones alfareras. Y en Fregenal-La Higuera, el horno de Alonso Yerro y Diego Pérez, en una casa de su propiedad, por lo que sería de carácter urbano.

Ya en la Sierra de Constantina, únicamente se indica para La Puebla de los Infantes que sus hornos de teja, ladrillo y tinajas pagaban el diezmo al almojarifazgo.

\subsection{Hornos de ollas}

Ollerías de productos cerámicos de cocina y vajillas. No fueron más comunes que las susodichas tinajerías. Comencemos, como en otros casos, por la Sierra de Aroche:

De ellas hubo seis en Aracena. La primera, como he apuntado más arriba, la de Hernando (o Fernando) García, sita en La Fuente. A falta de más referencias, puede que se tratase de alguna de las fuentes urbanas de la villa. Y, al no especificar cuál, sería, tal vez, de la más importante de ellas, la actual Gruta de las Maravillas, una de las mayores reservas de agua subterránea de la comarca, y uno de los fenómenos cársticos más bellos y espectaculares de toda España, como su nombre indica. La otra fuente a la que se pude estar haciendo mención puede que fuese la del Concejo; que vendría a ser la misma, no obstante, pues sus aguas proceden de la antedicha Gruta de las Maravillas ${ }^{28}$. Los restantes hornos de ollas parece que también estuvieron en el casco urbano de Aracena, de manera que se nutrirían de sus muchas fuentes, pues de ellos se dice - salvo del segundo, el de Hernando de Esteban, del que no se apunta nada - que estaban en un solar de casas (Esteban Domínguez), en un corral de la casa (Esteban Domínguez, Hernando Sánchez y Juan Bachiller), o simplemente en su casa (Martín Esteban).

En Aroche encontramos dos ollerías de Juan Simón; en una de ellas a veces cocían tinajas. Otra en Cumbres de San Bartolomé, del ollero Francisco Sánchez. Y la ya vista de Cumbres Mayores, del hospital de San Miguel. En Fregenal-La Higuera se produjo la cerámica más especializada o de calidad, la loza, de la cual hubo dos hornos sitos en casas del pueblo: el de Luis Jiménez y el del portugués Antón Falero ${ }^{29}$.

\footnotetext{
28 http://www.conocetusfuentes.com/ficha detalle.php?id fuente=2018. De he cho, el antedicho obtuvo otra licencia en 1499 para otra ollería, que puede que fuese la misma que la anterior pero que se recogiera en este año, a erigir en su casa y corral junto a la fuente del Concejo (http://www.conocetusfuentes.com/ficha_detalle. php?id fuente=52).

29 Frente a la cerámica común con una sola cocción, la loza o cerámica vidriada recibía una segunda, tras ser cubierta con un esmalte vítreo impermeable, lo que la convertía en más resistente y vistosa (Córdoba de la Llave, 1990, p. 328). Se han con-
} 
Finalmente, en Sanlúcar la Mayor, existieron cuatro hornos de ollería, en la collación de Santa María de San Lucas — pues, previamente a denominarse Santa María la Mayor, esta iglesia se llamó de San Lucas-; asimismo urbanos, por tanto: los de Alejo Tello, Gómez de Santillán (Sevilla), y los de los olleros Diego Martínez y Jerónimo González. Además, para Aznalcázar y Paterna se han conservado licencias de hornos de labor de barro; para la primera, de 1480, dada a Diego Sánchez Blanco y a su mujer, Inés Sánchez; para la segunda, de 1498, a Pedro de Herrera ${ }^{30}$.

\subsection{Tejares}

En cuanto a los hornos de tejas o tejares, son los más numerosos. Sin duda porque su producción (tejas y ladrillos) se usaba in situ, como los de cal que ahora veremos, para la erección y reparación de edificios locales. De modo que tales artículos, más bastos y pesados, no serían objeto de comercio a largas distancias, sino que su elaboración, más sencilla y sin grandes requerimientos técnicos ni de calidad, permitía fabricarlos casi a pie de obra, con lo que se ahorraba el coste de su transporte, cuando su mayor peso encarecía sobremanera su importación desde puntos no demasiado lejanos. Algo totalmente diferente a lo ocurrido con los objetos cerámicos, que requerirían de barros y arcillas de más calidad, que no se encontraban en todas partes, así como de artesanos especializados. De forma que su mayor valor y menor peso facilitaban importarlos desde aquellos lugares cuya ventaja competitiva, por la dotación de recursos (como abundancia de agua o de barro) y por la especialización técnica permitía confeccionarlos con mayor perfección y/o a menor precio.

En Aracena, como siempre, la más dotada de instalaciones industriales, encontramos nada menos que 18, 2 en Galaroza y 3 en Hinojales. Lo que, junto a la abundancia de hornos de cal, que ahora veremos, nos habla de la gran actividad edilicia de este municipio a finales del siglo XV; fruto, sin duda, de su alto crecimiento demográfico. De manera que la mayor parte de esta producción sería para la construcción local, más que para la exportación. Ya he apuntado que este crecimiento de la población tuvo lugar a finales de esa centuria, pues de buena parte de los inmuebles industriales se dice que habían sido erigidos solo unos años atrás. Comencemos por los de la propia villa de Aracena, para ir luego, como en los casos anteriores, y como casi siempre hacen las relaciones que estoy analizando, a sus aldeas y montes.

servado las licencias para dos ollerías en Cortegana, una dada en 1492 al escribano Juan Gandallo, en su huerta, junto al Chanza; y la otra en 1500, a Fernán Domínguez escribano, y Juan Márquez Nazarón (González Arce, 2020, apéndices).

30 También se dio una licencia en Utrera, en 1502, a Alfonso de Villamayor (González Arce, 2020, apéndices).
En primer lugar hay que hablar de tres hornos particulares, pues el resto eran concejiles o de las aldeas: el primero el de Antón Fontes, edificado por su padre Diego Fontes, hacía 20 años en un arrabal de la villa llamado Guadalupe - no sabemos a qué entorno actual correspondería, pero al norte de la localidad, a unos 0,5 km, hoy se encuentra un paraje llamado Los Hornos, topónimo que puede se remontase, como en otros casos, a tiempos medievales-; luego estaba el horno de la mujer de Juan Infante, en su tierra; y el de Luis y Antón Hernández, también en la suya. Vienen después los dos hornos del concejo, uno en el camino de Sevilla (donde hoy hay un paraje conocido como Fábrica de Cerámica) y el otro en el Campo de Don Andrés (no sabemos dónde se encontraría este posible monte, o población de tipo disperso). Otro estuvo en la aldea de Linares (Linares de la Sierra), y era propiedad de sus vecinos; sin duda para la erección de sus viviendas, en una de estas aldeas aracenenses que por entonces estaban experimentado un gran crecimiento demográfico. Mismo caso que Orullos, Casas de Juan Martínez, Las Carboneras, Aldea de Los Molinos (el arriba visto Arroyo de los Molinos), El Puerto (Puerto del Moral o Puerto Gil), Los Granados, Los Borzanos y Val del Arco donde también hubo otros tejares.

En otra de las aldeas, Galaroza, que contó con una pesquisa propia, por tener numerosos molinos, como sabemos, aparecen otros dos hornos de tejas: uno cabo la fuente que está cerca del lugar (hoy llamada de Nuestra Señora del Carmen); muy antiguo, propiedad de la ermita de Santa María de los Ángeles. Y, el otro en Navahermosa (cerca de esta otra aldea), que hacía dos años lo habían levantado sus vecinos para servicio de sus casas en tierras de uno de ellos, Toribio Martínez. Mismo caso que otra de las aldeas, Hinojales, que también tuvo su propia encuesta, en la que constan tres tejares más: uno del alcalde Antón Martínez, en sus tierras, que fabricaba para sus propias obras y para vender al público; otro de los herederos de Alonso Martínez, asimismo en sus posesiones, en el arroyo de la Corte (que hemos visto más arriba); y, el último el de Diego Martínez y de Juan Pérez, que estaba en sus casas, y que, como el primero, cocía para sí mismos y para la venta a otros.

Del mismo modo, al menor crecimiento demográfico de Aroche se correspondió un menor número de tejares. Apenas un horno de un particular, Alonso Rodríguez Jijas, en una huerta suya que estaba hacia la Fuente Vieja ${ }^{31}$; y dos del concejo, en los que cuando cocían los vecinos para sus casas, no pagaban nada, pero si lo hacían para vender abonaban almojarifazgo. Si seguimos este barómetro demográfico imperfecto, Cumbres de San Bartolomé y Mayores debieron experimentar por esos años un crecimiento de su población algo mayor, pues contaron con más tejares. Cuatro en la primera: el horno de la mujer de Pedro Díaz, sito en El Bodonal (que no sería la aldea de Fregenal, sino un paraje situado al este de Cumbres, llamado hoy Huerta Bodonal), en su tierra; el de Martín Vicente, también en su tierra; el de Juan Fernández, en un corral cerrado suyo cerca de los campos; y uno último, el de la aldea de la Cozcorrilla (¿Corchadillas?, al sur del pueblo, junto al Múrtigas), propiedad de Pedro Álvarez. Y cinco hornos en cumbres Mayores,

\footnotetext{
${ }^{31}$ En la actual pedanía arochena de las Cefiñas, al noreste del pueblo, se encuentra la Fuente Vieja (http://www.conocetusfuentes.com/ficha_detalle.php?id_fuente=56).
} 
cuatro solo de tejas y ladrillos: el de Alonso Sánchez Campoy, en Fuente el Arena, en su tierra; el de Pedro Martínez Figuero, en la suya; el de Martín Sánchez del Portal, en el arroyo Pedrona (el barranco de Pedrona separa los términos de Cumbres Mayores y Cumbres de Enmedio), en sus predios; y el de Fernando Martínez del Alamojuro, con las casas, en un corral suyo; y uno mixto, de tinajas y tejas, el ya visto del Hospital de San Miguel. Encinasola tuvo tres tejares o tejeras: el horno de Catalina Vázquez, la Delgada, en su casa; el de Juan Manuel, en la suya, con unos 8 años, sin merced ni tributo, pero sí almojarifazgo; y, el del tejero Juan García, en la cuadra de San Pedro (ermita de San Pedro, cercana al barranco de la Presa), en su tierra. Finalmente, en Fregenal-La Higuera hubo seis tejares más: el horno de Pedro Álvarez, en su tierra; el que lindaba con el molino de Diego Vázquez — que estaba en la rivera de la Fuente de las Huertas-, propiedad de Juan Álvarez; el de Pedro Álvarez, hortelano que puede fuese la misma persona de más arriba, junto al anterior —hoy día, al norte del arroyo de las Huertas y del arroyo Calderón, que discurre paralelo a él para confluir ambos más abajo, a la altura del pueblo, hay un paraje llamado Casas del Tejar y otro Cortijo del Tejar-; el de Diego Pérez, colindante con la dehesa del concejo (que sería la mencionada más arriba), en su huerta; el de Juan Pérez, hijo del anterior, en el corral de la casa de su hermano; y, el de Diego Vázquez, al igual que el de Pedro Álvarez, junto a su molino y en su tierra ${ }^{32}$

En la Sierra de Constantina, únicamente aparece un tejar en El Pedroso, el de Juan de Figueroa y de Pafo de Pineda. Aunque, no obstante, sí nos ha llegado una licencia de 1497 para la edificación de otro, dada a Juan Cabrera en su huerta del arroyo de la Madroñera, que nace al suroeste del pueblo, muy cerca del mismo (González Arce, 2020, apéndices).

En el Aljarafe, Hinojos contó con tres hornos de teja y ladrillo: uno del veinticuatro sevillano Gonzalo de Cuadros, en su heredad de la Torre - actualmente, al noreste del pueblo se localiza la Dehesa de Torrecuadros y el Cortijo de Torrecuadros-; otro concejil, en el arroyo de Muros, en el que cuando labraban algunos vecinos del lugar, de tarde en tarde, pagaban a la renta, y se encontraba desbaratado en parte, por lo que los que lo recibían para trabajar debían adobarlo antes; y, el último, también concejil en el pago de la Dehesa — hoy la Dehesa de Propios se encuentra al oeste de la localidad - , desde hacía 10 años cedido a Rodrigo Cataneo, sevillano difunto, a cambio de pagar al concejo 500 labores (tejas o ladrillos), el cual, algunos años, lo cedió a su vez a ciertos vecinos del lugar a cambio de la poya. Aznalcázar apenas tuvo dos tejares: uno junto a la villa, de Antón Gil de Grajeda; y el otro cercano a ella, de Pedro de Utrera - actualmente al norte de la población hay un paraje llamado Los Barros-.

\subsection{Caleras}

La cal es óxido de calcio que se obtiene de la combustión de piedras calizas en hornos. Se utiliza tanto como mortero, mezclada con arena, como aglutinante de los elementos constructivos, o para encalar las paredes, diluida en agua (Córdoba de la Llave, 1990: 307).

Al tratarse de un elemento clave en la erección de edificios, estos hornos de cal abundaron en la Sierra de Aroche a finales del siglo XV, única comarca en la que los encontramos, en plena expansión demográfica, como estamos viendo, que relanzó la actividad edilicia de la zona. En Aracena eran tantos que no se da cuenta de cada uno de ellos, pues no estaban gravados fiscalmente. Se dice en las pesquisas que había muchos hornos de cal en el término de la villa, todos concejiles, algunos antiguos y otros nuevos, y los hacía cualquier persona que quería fabricar cal en lo concejil, sin pedir licencia. Una vez cocido lo que querían, los abandonaban sin tener señorío sobre ellos. Además, Juan de Zafra, Diego Martínez Jacarillo y Juan Peña tenían el oficio de hacer cal para vender, pero no hornos conocidos para ello, sino que donde encontraban leña y piedras los levantaban. Algunos otros vecinos también hacían cal a veces para la venta, pero no lo tenían por oficio. En Galaroza no se los cita, pero sí en Hinojales, hasta cuatro, en este caso, al parecer, sí en posesión de particulares, aunque asimismo exentos: el de Martín Alonso, el monje, en el valle de la Alameda (sito al noroeste del pueblo, en el límite municipal con Cumbres Mayores); el de Gonzalo Martínez, carretero; el de Diego Díaz, en Los Prados (al noreste del pueblo); y, el de Juan Sánchez Guijarro, almojarife, en su tierra, en el camino de Sevilla.

En los restantes concejos de la Sierra, Aroche tuvo 7-8 hornos muy antiguos, posiblemente de cuando se fundó la villa, igualmente concejiles, libres y exentos; Cumbres de San Bartolomé, otro concejil, en la Dehesa de Encima (situada al sur de la población, junto al barranco del Higuerón, que va a dar al arroyo de la Dehesa, que desemboca en el Múrtigas), cuya cal era para la obra de la iglesia de San Bartolomé; y, Fregenal-La Higuera, 5 caleras asimismo exentas: el horno de Fernando García Cabrero, en su tierra; el de Santa Catalina, para la erección de esta iglesia de Fregenal, o puede que de La Higuera, donde hay otra de Santa Catalina Mártir; el de San Esteban, para este otro templo (que puede sea el actual de Santa Ana frexnense, que cuenta con una imagen del santo en su retablo); el de Santa María de Loreto, en La Higuera, igualmente para este edificio; y, el de Alonso Delgado, en la sierra de Hadraga.

\section{Conclusión}

La mejor manera de concluir este trabajo es intentar confirmar la hipótesis de partida, sobre si fue una mayor dedicación

\footnotetext{
32 En 1494 Juan Gandullo obtuvo una licencia para un tejar en Cortegana, en un sola suyo, cerca de la fuente Vieja, sita hoy en el casco urbano del pueblo (González Arce, 2020, apéndices; http://www.conocetusfuentes.com/ficha_detalle.php?id_fuente=2083).
} 
a actividades industriales rurales — toda vez que la industria urbana se concentraría en la capital-, para las que estaban especialmente dotadas, lo que llevó a las localidades serranas del norte del reino de Sevilla a situarse a la altura, e incluso superar a veces en desarrollo económico y población, a otras más dotadas para la agricultura de las zonas llanas del Aljarafe y la Campiña. Para ello, lo mejor será comentar los datos de la tabla 1 de la Introducción e interpretarlos mediante la información de las páginas precedentes.

Según dicha tabla, las villas que más desarrollo demográfico experimentaron entre la primera mitad del siglo XV y finales del mismo fueron las de las sierras de Constantina, sobre todo Castilblanco (con un 572\%) y Castillo de las Guardas (411\%) aunque a veces, a efectos fiscales aparezcan en la comarca de la Sierra de Aroche-, y las de la Sierra de Aroche, sobre todo Cortegana (403\%) y Aracena (396\%); frente al crecimiento moderado de la Campiña y casi nulo del Aljarafe. Así que, como hemos podido comprobar, aumentaron más sus vecinos las que contaron con mayor número de instalaciones industriales hidráulicas y alfareras y, por tanto, con una actividad manufacturera más intensiva. O a la inversa, la mayor dotación para la industria rural permitió a estas localidades crecer más en población en términos relativos $y$, a veces, absolutos. $O$ una última interpretación: el aprovechamiento de sus ventajas comparativas hasta entonces infrautilizadas, permitió a los núcleos de montaña explotar su potencial económico, para acercarse a finales del siglo XV en densidad de población a los más desarrollados agrícolas de valles y llanuras. Así, las rentas que gravaron la producción local de estas sierras se incrementaron en un 769\% para Cortegana, un $734 \%$ para Aracena o un 696\% para Cumbres Mayores; aunque aquí el crecimiento demográfico fue menor, pues el incremento de la recaudación fiscal podía no provenir de actividades industriales, que sí precisaban de más mano de obra, sino simplemente del aumento del tránsito de mercancías o ganados trashumantes por una zona, como es el caso, lo que no tenía demasiada repercusión económica ni demográfica local. Fuera de las sierras, solamente estuvo a este nivel de subida en su recaudación fiscal Utrera (734\%) y, a no mucha distancia, Lebrija (300\%); pero aquí, como en Cumbres Mayores, sin paralelo desarrollo demográfico, pues estos ingresos crecientes provinieron, en buena medida, del mayor tráfico comercial por la comarca, al caer el reino de Granada y desaparecer la peligrosa y próxima frontera con el mismo.

Parece pues, que la hipótesis inicial se confirma. Pero conviene hacer un análisis más pormenorizado para comprobarlo. Para ello habrá que ir a Aracena, el concejo que desde el principio hemos visto más dotado para la industria rural de montaña, con mayor número de instalaciones de este tipo; que, y ahora ya se puede decir, gracias a ellas fue el que más vio aumentar su población. Puesto que, si le sumamos los incrementos de sus dos grandes aldeas, Hinojales (con un 1.037\%) y Galaroza (600\%), que a efectos de vecinos —en los padrones fiscales para las contribuciones de los pecheros - se contabilizaron aparte, hemos de tenerla por la población que más mejoró sus efectivos.

Precisamente ahí está la clave del éxito aracenense, la aparición de numerosas aldeas (núcleos de población concentrada pero no muy numerosa) y campos (asentamientos disper- sos) en su término, para aprovechar el potencial industrial del entorno serrano. Hinojales pudo pasar de 8 a 91 vecinos (de unos 40 habitantes a unos 455), en apenas 50 años, en parte porque en ese período construyeron o pusieron en marcha, como hemos visto, unos 5 molinos harineros, 3 tejares y 4 hornos de cal. Mientras que Galaroza, que subió de 8 vecinos a 56 (de 40 habitantes a unos 280, en 58 años), lo hizo gracias, en parte, a sus 6 molinos harineros, su batán y sus 2 tejares. Más evidente puede que fuese el ejemplo de Arroyo de los Molinos, aldea que nació para que sus 13 vecinos (en 1486) ${ }^{33}$ hiciesen funcionar sus 8 molinos de grano y sus 2 batanes. Caso similar a otras aldeas arriba vistas como Orullos (25 vecinos), Las Carboneras (10), Val del Arco (9) o Las Chinas, donde también hubo instalaciones alfareras.

No se trató de una situación exclusiva de Aracena y su entorno, sino que se repitió en Cortegana y La Nava, con sus 10 ingenios hidráulicos; o con Fregenal y La Higuera, con sus 27 artefactos y numerosos hornos cerámicos, que llevaron a esta última localidad de 51 vecinos a 348, en apenas 63 años, un incremento del 582\%, como se aprecia en la tabla 1. Pero, además, en este último caso, como en otros muchos de las sierras, habría tenido también gran relevancia en el despegue demográfico el cultivo y manufactura del lino; una industria lencera que, como no ha dejado huella edilicia, y que de momento solamente se puede cuantificar por la renta del peso del lino, desagregada por entonces de muchos almojarifazgos locales, como dije más arriba, no he abordado en este trabajo. También dejo para otra ocasión el análisis de los propietarios de estos inmuebles productivos que, como se ha podido ver a lo largo del estudio, eran en muchos casos empresarios inversores, a veces llegados de fuera del lugar, que con estas instalaciones, en especial los molinos, buscaban beneficios al ponerlas al servicio de habitantes de fuera de la comarca, donde la menor dotación de recursos hacía menos rentable la molienda de grano, el batanado de paños o la fabricación de productos cerámicos.

\footnotetext{
33 Pérez-Embid Wamba, 1998: 130-131. Los datos demográficos de las demás aldeas están tomados de estas mismas páginas.
} 
Bibliografía

ARACIL, R. y GARCÍA BONAFÉ, M. (1974): "Industria doméstica e industrialización en España", Hacienda Pública Española, 55.

BERNAL, A.M., COLLANTES DE TERÁN, A. y GARCÍA-BAQUERO, A. (1978): "Sevilla: de los gremios a la industrialización", Estudios de historia social, 5-6.

BORRERO FERNÁNDEZ, M. (1983): El mundo rural sevillano en el siglo XV: Aljarafe y Ribera, Sevilla, Diputación Provincial.

CARRASCO TEZANOS, A. (2006): La sociedad campesina en la Sierra de Guadarrama a finales de la Edad Media, Al-Mudayna, Madrid.

COBOS RODRÍGUEZ, J.J. (2018): Documentos de los Reyes Católicos sobre Antequera en el Archivo General de Simancas, Registro General del sello (1475-1501), Libros EPCCM, Granada.

COLLANTES DE TERÁN SÁNCHEZ, A. (1976): "La tierra realenga de Huelva en el siglo XV", Huelva en la Andalucía del siglo XV, II Jornadas de Estudios Medievales en Andalucía, Instituto de Estudios Onubenses Padre Marchena, Huelva.

COLLANTES DE TERÁN SÁNCHEZ, A. (1977): "Nuevas poblaciones del siglo XV en el reino de Sevilla", Cuadernos de Historia, (Anexos de Hispania), 7.

COLLANTES DE TERÁN SÁNCHEZ, A. (1998): “La tierra realenga de Huelva: Una imagen fiscal", Huelva en la Edad Media. Reflexiones, aportaciones y nuevas perspectivas veinte años después, Universidad de Huelva.

CÓRODOBA DE LA LLAVE, R. (1990): La industria medieval del Córdoba, Córdoba, Caja Provincial de Ahorros de Córdoba.

CÓRODOBA DE LA LLAVE, R. (1993): "Molinos y batanes de la Córdoba medieval", Ifigea, 9, pp. 31-56.

CÓRODOBA DE LA LLAVE, R. (2002): "Sobre el origen y difusión de los Molinos de Regolfo", III Jornadas de Molinología, Murcia.

FRANCO SILVA, A. (1987): El concejo de Alcalá de Guadaira a finales de la Edad Media, Sevilla, Universidad de Sevilla.

GARCÍA TAPIA, N. (1997): Los molinos tradicionales, Valladolid, Castilla Ediciones.

GARCÍA TAPIA, N. y CARRICAJO, C. (1990): Molinos de la provincia de Valladolid, Valladolid, Cámara Oficial de Comercio e Industria.

GONZÁLEZ ARCE, J.D. (2020): Un patrimonio concejil ingente: el almojarifazgo de los pueblos de Sevilla (ss. XIII-XV), Murcia, Sociedad Española de Estudios Medievales.

GONZÁLEZ ARCE, J.D. (en prensa 1): "Inmuebles de los pueblos de Sevilla dedicados a actividades económicas a finales del siglo XV".

GONZÁLEZ ARCE, J.D. (en prensa 2): "La red molinar de la Sierra Morena occidental en el siglo XV".

GONZÁLEZTASCÓN, I. (2009): "Molinos y otros ingenios en tiempo del Quijote", Actas V Congreso Internacional de Molinologia, Junta de Comunidades de Castilla La Mancha, Alcázar de San Juan.

GONZÁLEZ ENCISO, A. (1984): "La protoindustrialización en España", Revista de Historia Económica, 2, 1.

KRIEDTE, P. MEDICK, H. y SCHLUMBOHM, J. (1986): Industrialización antes de la industrialización, Barcelona, Crítica.

MARTíNEZ MARTíNEZ, M. (1987): "Molinos hidráulicos en Murcia (ss. XIIIXV)", Miscelánea Medieval Murciana, 14, pp. 219-250.

MENDELS, F. (1972): "Protoindustrialization: the first phase of the Industrialization Process", Journal of Economic History, 32.

MÉNDEZ-CABEZA FUENTES, M. (1998): Los molinos de agua de la provincia de Toledo, Toledo, Institución Provincial de Investigaciones y Estudios Toledanos.

PÉREZ GALLEGO, M. (1992): Antequera a fines del siglo XV, Editorial Algazara.
PÉREZ-EMBID WAMBA, J. (1996): Aracena y su sierra. La formación de una comunidad andaluza (siglos XIII-XVIII), Huelva, Diputación Provincial.

PÉREZ-EMBID WAMBA, J. (1998): "Las Sierras de Aroche y Aracena: la formación de una unidad comarcal en el Reino de Sevilla durante la Baja Edad Media", Huelva en la Edad Media: reflexiones, aportaciones y nuevas perspectivas veinte años después, Huelva, Universidad de Huelva.

RUCQUOI, A. (1983): "Molinos et aceñas au coeur de la Castille septentrionale", Les espagnes médiévales : aspects economiques et sociaux : mélanges offerts à Jean Gautier Dalché, Les Belles Lettres.

SÁNCHEZ BENITO, J.M. y MELA MARTíN, C. (1989): “Los molinos hidráulicos en el sistema agrario del siglo XV a través de un ejemplo. El Monasterio de Santa María de Aguilar de Campo", Publicaciones de la Institución Tello Téllez de Meneses, 60, pp. 100-114.

TOTTÓ GIL, L. (1994): "Sobre la protoindustrialització: Reflexions a partir d'un cas local, Alcoi (segles XVI-XIX)", Afers: fulls de recerca i pensament, 9.

TRIANO MILÁN, J.M. (2018): La llamada del rey y el auxilio del reino. Del pedido regio a las contribuciones de la Santa Hermandad (1406-1498), Sevilla, Universidad de Sevilla. 